\title{
The Impact of End-User Training on the Librarian's Status
}

End-user training's impact on the librarian's status is to be debated at an upcoming Medical Library Association Mid-Atlantic Chapter meeting. It will share the panel platform with other topics such as "who is the end user," "the impact of end-user searching on other library services," and "the costs associated with end-user searching."

When I first grappled with this topic, I had some difficulty imagining any negative effects of end-user training on the status of librarians. This activity seemed to provide further support for the status which others have viewed as associated with automation. As Schwartz states, "Automation has helped establish librarians as experts in the design of new hardware and software products and the development of new instructional programs." ${ }^{2}$ However, stepping back and using the editorial "we," I find that we are still trying to sell to each other the idea that teaching users to do their own online searching is a "Good Thing." The following is an overview of some of the arguments on both sides as they relate to the status of librarians. I have liberally used examples from the setting in which I work and conversations with colleagues.

\section{Positive Impact on Status}

A common anecdote told by teachers of end users is that class participants express a new appreciation of the librarian's expertise. More than one user has told me that, even though they may do their own routine searches, they contact the library to have complicated searches done because "you folks are the experts." I have heard many anecdotes about how the searches that librarians run for users have become more complex and time consuming which may reflect that this referral is indeed happening.

The status of consultant has evolved from teaching end users to do their own searching. As a direct result of our library's instructional programs for end user searching, we have become consultants for search software selection. We receive inquiries on hardware selection and telecommunications software as well, but have decided that our resources are best used if we refer these to another support center on campus. Instead, we have devoted our energy to other spin-off requests of end-user training: downloading, formatting bibliographies, and text management. Based upon the contacts and referrals we receive, we clearly have the status of campus experts in these areas. Further evidence of this was a request to recommend filing software for campus support, which we fulfilled two years ago.

The consultant status has also extended to being asked to cooperatively develop grant proposals in the area of use; interface design, educational tool development. and cognitive research associated with the

\footnotetext{
${ }^{1}$ Bader, S.G., moderator. "Managing the Invisible Searcher: Probing the Issues-Cost, Status, Impact on Services." Panel conducted at the Mid-Atlantic Chapter Medical Library Association Meeting, Charleston, WV, November 10, 1988.

2 Schwartz, D.G. "New Roles for the Medical Librarian in an Information Management Environment." Med Ref Serv Q 6(Winter 1987):28.
} 
tool. Our staff has also been asked for advice on the retrieval components of departmental databases, particularly in the use of controlled vocabulary and textword searching.

This new status is reflected in the appointments of library faculty to planning groups dealing with database access policies, integration of information technology into curricula, and campus electronic networking. Our staff is also asked to present campus programs on topics such as access to external databases, text management software, and software for formatting bibliographies.

There is continuing evidence that faculty view us as team players in the educational process. This partnership is described in the literature. ${ }^{3}$ A recent example in my own setting was a class for 150 medical students in which I team-taught a session with a faculty member in medicine: we jointly prepared and presented a clinical case study and search on failure-to-thrive, followed by small group instruction on SilverPlatter MEDLINE provided by members of our educational department. We have also been asked to jointly develop credit courses which include end-user searching as an element. Our department is presently in the position of not needing to drum up business. Our challenge is selecting those programs through which we can have the greatest impact on students and faculty-making the best use of our time and funds.

We are beginning to take on a formal advocacy role with vendors and producers, i.e., conducting beta tests of new software and documenting changes we and our users recommend. Whether or not we beta test a product, we try to provide producers with both formal and informal feedback. One of our staff recently submitted an extensive list of recommendations to the producer of PRO-CITE. It will be interesting to see if this role develops in the same fashion as the ones mentioned above.

Additional positive impact on the status of the librarian may yet lie in the future. If the time freed from some routine searches is put toward expanding our roles in synthesizing information, quality filtering, and database design activities, there will be another level of consciousness raising on the part of our users. The expertise required for these activities has always been with us but it will be more visible to our clientele, again having a beneficial impact on their perceptions of our role.

\section{Negative Impact on Status}

End-user training does have the result of getting us into areas for which librarians traditionally do not have training or experience or in which we are competing with other experts. A few examples are the areas of hardware selection, telecommunications software, and instructional design. This has the potential for creating a loss of credibility, particularly if thought is not given to the scope of services to be provided and identification of alternative sources of expertise.

As a result of end-user searching, users have less need to come to the library, particularly if document delivery can be requested remotely as well. According to Poisson, ". . . end-user searching results in low use of search services." 4 This may lead to less visibility for the library and librarians, particularly if attention is not given to publicity and promotion of the librarian's role. This could then undermine prior gains in status.

\footnotetext{
${ }^{3}$ Reidelbach, M.A. et al. "An Introduction to Independent Learning Skills for Incoming Medical Students." Bull Med Libr Assoc 76(April 1988):159-163.

${ }^{4}$ Poisson, E.H. "End-User Searching in Medicine." Bull Med Libr Assoc 74(October 1986):298.
} 
Competition with faculty is a potential mine field related to incorporating information management education in the curricula of health professions students. As Shedlock has noted, librarians may be viewed as rivals by faculty "who say they are better equipped to teach such courses." ${ }^{5}$ An example of this in a related area is the criticism our staff received from a vocal faculty member who disagreed with the filing software we recommended for campus support. The faculty member explicitly called into question our expertise to make such recommendations. The software review process and what we learned from it is documented by Stigleman. ${ }^{6}$

Some of the negative impacts on status may be a matter of self-perception rather than externally verified. For example, Welborn and Kuehn reported rewarding intangible results of end-user training. "Heightened self-esteem," "increased respect that patrons developed for librarians," and "mutual admiration relationship" are some of the phrases used by medical librarian respondents to their survey. ${ }^{7}$ On the other hand, Wykoff reports feelings of loss of feeling special and losing professional worth. ${ }^{8}$

A source of unknown, but possibly negative, impact is the difficulty we have in monitoring the success of end-user searches. A certain percentage of these searches will be of poor quality. Will the user be disillusioned with the librarian for promoting or providing a service which produces poor results? Without some way of monitoring this activity, we will be unable to minimize this negative impact by selecting a better product, providing user support, or other interventions.

\section{Not So Final Thoughts}

I have gained a new appreciation of both the negative and positive impacts of teaching end users how to do their own online searching. In my assessment, however, the positives outweigh the negatives in deciding whether or not to offer end-user searching. The negatives point out some pitfalls and resource implications that are critical to the success of such a program. The correlation of end-user searching with low use of mediated search services, which was pointed out above, may actually be an indication that end-user searching reaches a whole new audience for library services and exposes a new group to the librarian's expertise. This possibility is exciting and, as exemplified above, can reap some important benefits for the library.

Francesca Allegri

806 S. Foley Street

Champaign, IL 61820

Comments and suggestions should be sent to the Column Editor: Francesca Allegri.

\footnotetext{
${ }^{5}$ Shedlock, J. "Who's Responsible for Teaching Information Management?" Med Ref Serv Q 5(Summer 1986):79.

${ }^{6}$ Stigleman, S.E. "The Software Jungle: To Guide or Not to Guide." In Proceedings of the Ninth National Online Meeting, New York, May 10-12, 1988, compiled by M.E. Williams and T.H. Hogan. Medford, NJ: Learned Information, Inc., 1988.

${ }^{7}$ Welborn, V., and Kuehn, J.J. "End-User Programs in Medical School Libraries: A Survey." Bull Med Libr Assoc 76(April 1988):138.

${ }^{8}$ Wykoff, L.W. "Teaching Patrons to Search" Med Ref Serv Q 4(Summer 1985):59.
} 